\title{
HIF- $1 \alpha$ and CA-IX as predictors of locoregional control for determining the optimal treatment modality for early-stage laryngeal carcinoma
}

\author{
Oh Jin Kwon, MD, ${ }^{1}$ Jung Je Park, MD, ${ }^{*}$ Gyung Hyuck Ko, MD, ${ }^{2}$ Ji Hyun Seo, MD, ${ }^{2}$ Bae-Kwon Jeong, MD, ${ }^{2}$ Ki Mun Kang, MD, ${ }^{2}$ Seung Hoon Woo, MD, ${ }^{1}$ \\ Jin Pyeong Kim, MD, ${ }^{1}$ Jeong Seok Hwa, ${ }^{2}$ Thomas E. Carey, $\mathrm{PhD}^{3}$
}

${ }^{1}$ Department of Otolaryngology-Head and Neck Surgery, School of Medicine, Gyeongsang National University, Jinju, Korea, ${ }^{2}$ Department of Pathology, Radiation Oncology, CyberKnife Center, and Pediatrics, Gyeongsang National University, Jinju, Korea, ${ }^{3}$ Department of Otolaryngology-Head and Neck Surgery, Medical School, University of Michigan, Ann Arbor, Michigan.

Accepted 6 February 2014

Published online 9 April 2014 in Wiley Online Library (wileyonlinelibrary.com). DOI 10.1002/hed.23620

ABSTRACT: Background. The purpose of this study was to examine the predictive value of hypoxia-inducible factor $(\mathrm{HIF})-1 \alpha$, carbonic anhydrase (CA)-IX, glucose transporter (GLUT)-1, cyclooxygenase (COX)-2, $\mathrm{Ki}-67$, and erythropoietin receptor (EPOR) as immunohistochemical markers for determining the optimal treatment modality for early stage laryngeal carcinoma.

Methods. Tissue samples from 42 early stage laryngeal carcinomas treated with radiotherapy alone were analyzed immunohistochemically for the expression of 6 markers. The Kaplan-Meier method, univariate and multivariate analyses, and the Cox proportional hazards model were used to analyze the associations between patient and tumor characteristics and immunohistochemical results, and locoregional control.
Results. Increased expression of HIF- $1 \alpha$ and CA-IX was significantly correlated with residual tumor; no correlations were observed for the other immunohistochemical markers.

Conclusion. High levels of HIF-1 $\alpha$ or CA-IX expression were significantly correlated with residual tumor after radiotherapy for early stage laryngeal carcinomas. Alternative treatment modalities to primary radiotherapy should be considered for early stage laryngeal carcinomas showing high HIF-1 $\alpha$ or CA-IX expression. (C) 2014 Wiley Periodicals, Inc. Head Neck 37: 505-510, 2015

KEY WORDS: laryngeal carcinoma, radiotherapy, hypoxia-inducible factor-1 $\alpha$, carbonic anhydrase IX, glucose transporter-1

\section{INTRODUCTION}

Head and neck squamous cell carcinoma (HNSCC) is the fifth most common cancer in men and the eighth most common in women worldwide, with approximately 600,000 new cases each year. ${ }^{1}$ Despite improvements in treatment modalities, which include a combination of surgery, radiotherapy, and chemotherapy, the 5-year survival rate for patients with advanced disease is approximately $50 \% .^{2}$

Patients with HNSCC with similar histological grade and clinical stage often have different prognosis; these differences may be associated with the expression of specific immunohistochemical markers. Therefore, the identification of immunohistochemical markers associated with the clinicopathological features of HNSCC is very important. Endogenous hypoxia-related markers are associated with the prognoses of patients with different types of carcinoma. Clinically relevant hypoxia is detected in approximately $50 \%$ of all solid tumors. ${ }^{3}$ Hypoxia is the result of

*Corresponding author: J. J. Park, Department of Otolaryngology-Head and Neck Surgery, School of Medicine, Gyeongsang National University, 90 Chilamdong Jinju, South Korea, 660-702. E-mail: capetown@hanmail.net an imbalance between oxygen delivery and oxygen consumption, and is one of the most important events during carcinoma progression. ${ }^{4}$ Moreover, hypoxic tumor cells are resistant to radiation and to many anticancer drugs; therefore, many approaches to circumventing hypoxiainduced resistance have been examined in laboratory studies and clinical trials. ${ }^{5}$ A recent study investigating hypoxia-related biomarkers in early glottic cancer showed that overexpression of hypoxia-inducible factor (HIF) $-1 \alpha$ and carbonic anhydrase (CA)-IX was correlated with local failure. ${ }^{6}$ In addition to endogenous hypoxiarelated markers, several studies have examined immunohistochemical markers associated with the prognosis of patients with cancer.

In this study, we identified 6 immunohistochemical markers of potential prognostic significance in patients with early stage laryngeal carcinoma, one of the most common forms of HNSCC. These markers, which are also prognostically relevant for patients with carcinoma, include HIF-1 $\alpha$, CA-IX, glucose transporter-1 (GLUT-1), cyclooxygenase 2 (COX-2), Ki-67, and erythropoietin receptor (EPOR). The purpose of this study was to assess the clinical significance of these markers for predicting radioresistance and residual tumor after radiotherapy in a consecutive series of 42 patients who underwent primary radiotherapy for early-stage (T1 and T2) squamous cell carcinoma of the larynx. 


\section{MATERIALS AND METHODS}

\section{Patients}

Forty-two patients with early-stage (T1 and T2) squamous cell carcinoma of the larynx treated at the Department of Otolaryngology-Head and Neck Surgery at Gyeongsang University Hospital, Jinju, Korea, between 1991 and 2009 were examined. Of these, 29 had glottic (T1, 26; T2, 3) and 13 had supraglottic (T1, 2; T2, 11) tumors. All patients were treated with continuous course radiotherapy (once daily, 5 days per week) using a linear accelerator. Patients with glottic cancer received a median total dose of 6628 cGy (range, 6000-7020 cGy) administered in daily $180-$ to $225-c G y$ fractions using the parallel-opposed 2-field technique. Patients with supraglottic cancer received a median total dose of 6968 cGy (range, 6600-7020 cGy) administered in daily 180- to 200-cGy fractions using the 3-field technique (opposed lateral field and lower anterior field) for elective nodal irradiation. The inclusion criteria were histologically proven squamous cell carcinoma of the larynx, stage T1 to $\mathrm{T} 2$, and curative treatment with radiotherapy alone. Demographic and clinicopathologic data, including sex, age, pretreatment hemoglobin level, and T category, were retrospectively collected by reviewing the patients' charts. Anemia was defined as a $\mathrm{Hb}$ level $\leq 11 \mathrm{~g} / \mathrm{dL}$ based on previously published studies in patients with HNSCC. ${ }^{7}$

\section{Tissue microarrays}

Paraffin-embedded, pretreatment biopsy specimens containing sufficient carcinoma cells for immunohistochemical staining were available. Core tissue biopsies $(2 \mathrm{~mm}$ in diameter) were obtained from individual formalin-fixed and paraffin-embedded archival tissue (donor blocks) and arranged in a new recipient paraffin block using a trephine apparatus (The Quick-RAY, Unitma, Seoul, Korea). One tissue core from the most representative portion was analyzed in each case. The collection of specimens was approved by the Gyeongsang University Hospital Institution Review Board, Jinju, Korea.

\section{Immunohistochemistry}

Immunohistochemical staining was performed on $4-\mu \mathrm{m}$ thick sections as follows: sections were deparaffinized and rehydrated and then incubated in $3 \% \mathrm{H}_{2} \mathrm{O}_{2}$ for 10 minutes to reduce nonspecific background staining caused by endogenous peroxidases. For epitope retrieval, specimens were placed in $10 \mathrm{mmol} / \mathrm{L}$ citrate buffer $(\mathrm{pH} 6.0)$ and heated in a microwave oven (700 watts) for 20 minutes. After incubation with Ultra V Block (Lab Vision, Fremont, CA) for 7 minutes at room temperature to block background staining, the slides were incubated with rabbit polyclonal anti-COX-2 (dilution 1:100; Epitomics, Burlingame, CA), mouse monoclonal anti-GLUT-1 (dilution 1:200; Thermoscientific, Fremont, CA), mouse monoclonal anti-Ki-67 (dilution 1:1000; DAKO, Carpinteria, CA), rabbit polyclonal anti-CA-IX (dilution 1:1000; Novus Biologicals, Littleton, CO), rabbit polyclonal antiHIF-1 $\alpha$ (dilution 1:200; Epitomics) or rabbit polyclonal anti-EPOR (dilution 1:100; Santa Cruz Biotechnology, Santa Cruz, CA) antibodies at room temperature. Anti-
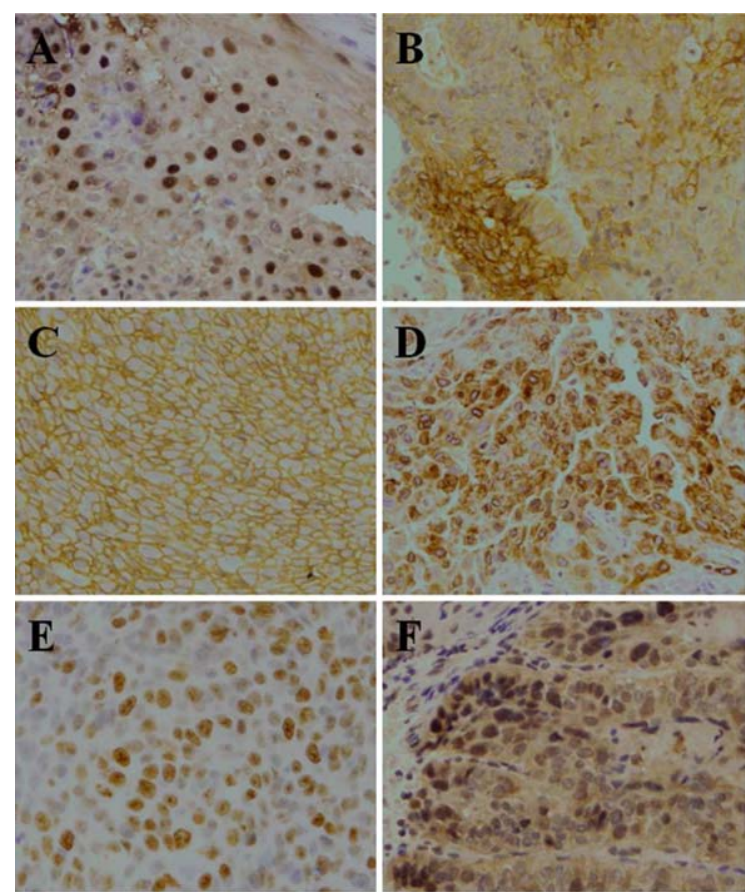

FIGURE 1. Positive staining for immunohistochemical markers. (A) Hypoxia-inducible factor-1 $\alpha$ (HIF-1 $\alpha$ ), (B) carbonic anhydrase 9 (CA-IX), (C) glucose transporter-1 (GLUT-1), (D) cyclooxygenase 2 (COX-2), (E) Ki-67, and (F) erythropoietin receptor (EPOR). Original magnification, $\times 200$. [Color figure can be viewed in the online issue, which is available at wileyonlinelibrary.com.]

body binding was detected using the UltraVision LP detection system (Lab Vision) in accord with the manufacturer's recommendations. Color development was performed with 3-3'-diaminobenzidine and the slides were counterstained with hematoxylin.

\section{Assessment of protein expression}

Antigen expression was examined by an investigator who was blinded to the clinical data. For COX-2, GLUT1 , Ki-67, and HIF- $1 \alpha$, the samples were scored according to the percentage of positively stained cells as follows: $1+, 1 \%$ to $10 \% ; 2+, 11 \%$ to $50 \% ; 3+, 51 \%$ to $80 \%$; and $4+,>80 \%$ of cancer cells stained. For CA-IX, the samples were scored as follows: $1+, 1 \%$ to $10 \% ; 2+, 11 \%$ to $30 \% ; 3+, 31 \%$ to $50 \%$; and $4+,>50 \%$ of positively stained cancer cells. A cutoff point was used to define 2 groups of low and high expression: negative, $1+$, or $2+$ staining patterns were regarded as low expression. The staining patterns $3+$ and $4+$ were regarded as high expression patterns. For EPOR, the samples were considered positive if $50 \%$ or more cancer cells were stained. Negative was classified as low expression; positive was classified as high expression (Figure 1).

\section{Statistical analysis}

Locoregional control was analyzed using the KaplanMeier method and prognostic factors were assessed using the log-rank test. Univariate and multivariate analyses and the Cox proportional hazards model were used to analyze 
TABLE 1. Clinical and pathologic characteristics of patients.

\begin{tabular}{|c|c|}
\hline Characteristic & No. of patients (\%) \\
\hline \multicolumn{2}{|l|}{ Sex } \\
\hline Male & 37 (88.1) \\
\hline Female & $5(11.9)$ \\
\hline \multicolumn{2}{|l|}{ Age, y } \\
\hline Median & 63.5 \\
\hline Range & $34-88$ \\
\hline \multicolumn{2}{|l|}{ Primary site } \\
\hline Supraglottis & $13(30.9)$ \\
\hline Glottis & $29(69.1)$ \\
\hline \multicolumn{2}{|l|}{ T classification } \\
\hline $\mathrm{T} 1$ & $28(66.7)$ \\
\hline T2 & $14(33.3)$ \\
\hline \multicolumn{2}{|c|}{ Hemoglobin level $(\mathrm{mmol} / \mathrm{L})$} \\
\hline High (>11 mmol/L) & 40 (95.2) \\
\hline Low $(<11 \mathrm{mmol} / \mathrm{L})$ & $2(4.8)$ \\
\hline \multicolumn{2}{|l|}{ GLUT-1 expression } \\
\hline High & $28(66.7)$ \\
\hline Low & $14(33.3)$ \\
\hline \multicolumn{2}{|l|}{ COX-2 expression } \\
\hline High & $29(69.0)$ \\
\hline Low & $13(31.0)$ \\
\hline \multicolumn{2}{|l|}{ Ki-67 expression } \\
\hline High & $8(19.0)$ \\
\hline Low & $34(81.0)$ \\
\hline \multicolumn{2}{|l|}{ CA-IX expression } \\
\hline High & $17(40.5)$ \\
\hline Low & $25(59.5)$ \\
\hline \multicolumn{2}{|l|}{ HIF-1 $\alpha$ expression } \\
\hline High & $7(16.7)$ \\
\hline Low & $35(83.3)$ \\
\hline \multicolumn{2}{|l|}{ EPOR expression } \\
\hline High & $17(40.5)$ \\
\hline Low & $25(59.5)$ \\
\hline
\end{tabular}

Abbreviations: GLUT, glucose transporter; COX, cyclooxygenase; CA-IX, carbonic anhydrase 9; HIF, hypoxia-inducible factor; EPOR, erythropoietin receptor.

the association between patient and tumor characteristics and immunohistochemical results, and locoregional control.

Residual tumor was defined as tumor tissue detected within 6 months from the last day of radiotherapy. Locoregional recurrence was defined as tumor recurrence at the primary tumor site after 6 months from the last day of radiotherapy.

Differences were considered statistically significant when $p<.05$. All statistical analyses were performed using the Statistical Package for Social Sciences, version 14.0.0 (SPSS, Chicago, IL).

\section{RESULTS}

\section{Follow-up data}

The clinicopathologic characteristics of the patients included in the study are shown in Table 1 . The mean follow-up period was 89 months (range, 6-206 months) at the time of the study. Of the 42 patients enrolled, 4 died of their disease, 7 died of other causes, and 31 were alive at the last follow-up. Six patients $(14.3 \%)$ had residual tumor after primary radiotherapy and 11 patients $(26.2 \%)$ developed local recurrence. Seventeen patients $(40.5 \%)$ presented with residual or recurrent locoregional disease after primary radiotherapy. Of the 17 patients with residual or recurrent tumor, 10 underwent total laryngectomy. Of the remaining 7 patients, 2 refused other treatment and 5 received conservative laryngeal surgery. Immunohistochemical staining of tissue microarrays showed that most tumors were negative or weakly positive for HIF-1 $\alpha$ and Ki-67 and moderately or strongly positive for CA-IX, COX-2, GLUT-1, and EPOR.

\section{High hypoxia-inducible factor-1 $1 \alpha$ or carbonic anhydrase- IX expression level predicts residual tumor}

Univariate Cox regression analysis showed that high HIF- $1 \alpha$ (hazard ratio [HR], 5.17; 95\% confidence interval $[\mathrm{CI}], 1.043-25.618)$ and CA-IX (HR, 8.65; 95\% CI, 1.010-74.095) expression were predictive of residual tumor (Table 2); this was confirmed by the Kaplan-Meier survival curves (Figure 2A and 2B). Low expression of HIF- $1 \alpha$ and CA-IX was significantly associated with better locoregional control (Figure 2C); however, high HIF$1 \alpha$ and CA-IX expression was not predictive of locoregional recurrence (Figure 2D and2E). There was no statistically significant association between locoregional control and other clinicopathological variables (age, T classification, hemoglobin level, and other immunohistochemical markers). Kaplan-Meier survival curves showed no significant association between any of the immunohistochemical markers and disease-specific survival.

\section{Multivariate analysis}

On multivariate Cox regression analysis, high CA-IX expression (HR, 72.29; 95\% CI, 3.239-1613.499) was significantly associated with residual tumor (Table 3).

\section{DISCUSSION}

In early glottic cancer, radiotherapy alone has been reported to be about $80 \%$ to $90 \%$ effective for local control of T1 glottic cancer and $65 \%$ to $80 \%$ effective for T2 glottic cancer. ${ }^{8}$ According to recently published guidelines for the treatment of head and neck cancer, all patients with T1 to T2 laryngeal cancer should be treated, at least initially, with the intent of larynx preservation. The recommended strategies for early laryngeal cancer with the intent of larynx preservation are radiation therapy, transoral laser therapy, and partial laryngectomy. ${ }^{8}$

Surgery and radiotherapy are well established and effective treatment modalities for early-stage laryngeal carcinoma. Both show similar local control and survival rates, although radiotherapy is associated with better functional results. ${ }^{6}$ Because the larynx is an important organ for vocalization, breathing, and swallowing, the optimal management of early-stage laryngeal carcinoma is aimed at treating the tumor while preserving laryngeal function. Radiotherapy is a generally accepted treatment modality that meets both of these criteria, and its association with the preservation of laryngeal function has made it the predominant treatment for early-stage laryngeal carcinoma in most countries.

Tumor hypoxia is a well-known prognostic factor for locoregional control after primary radiotherapy. A large body of clinical evidence suggests that tumor hypoxia has a negative impact on the outcome of radiotherapy. ${ }^{9}$ 
TABLE 2. Patient and disease characteristics related to residual tumor after radiotherapy.

\begin{tabular}{|c|c|c|c|c|}
\hline Characteristic & Total & Residual tumor & Univariate $\mathrm{HR}(95 \% \mathrm{Cl})$ & $p$ value \\
\hline Age, y & & & & .890 \\
\hline$>60$ & 13 & 2 & 1 & \\
\hline$\leq 60$ & 29 & 4 & $0.89(0.163-4.846)$ & \\
\hline T classification & & & & .395 \\
\hline T1 & 28 & 3 & 1 & \\
\hline $\mathrm{T} 2$ & 14 & 3 & $2.00(0.404-9.926)$ & \\
\hline Hemoglobin level & & & & .233 \\
\hline High ( $>11 \mathrm{mmol} / \mathrm{L})$ & 40 & 5 & 1 & \\
\hline Low $(<11 \mathrm{mmol} / \mathrm{L})$ & 2 & 1 & $3.69(0.431-0.31 .628)$ & \\
\hline GLUT-1 expression & & & & .383 \\
\hline High & 28 & 5 & $2.60(0.304-22.257)$ & \\
\hline Low & 14 & 1 & 1 & \\
\hline COX-2 expression & & & & .890 \\
\hline High & 29 & 4 & $0.887(0.163-4.846)$ & \\
\hline Low & 13 & 2 & 1 & \\
\hline Ki-67 expression & & & & .374 \\
\hline High & 8 & 2 & $2.16(0.396-11.803)$ & \\
\hline Low & 34 & 4 & 1 & \\
\hline CA-IX expression & & & & $.049 *$ \\
\hline High & 17 & 5 & 8.65 (1.010-74.095) & \\
\hline Low & 25 & 1 & 1 & \\
\hline HIF-1 $\alpha$ expression & & & & $.044^{*}$ \\
\hline High & 7 & 3 & $5.17(1.043-25.618)$ & \\
\hline Low & 35 & 3 & 1 & \\
\hline EPOR expression & & & & .764 \\
\hline High & 17 & 2 & $0.77(0.141-4.210)$ & \\
\hline Low & 25 & 4 & 1 & \\
\hline
\end{tabular}

Abbreviations: HR, hazard ratio; Cl, confidence interval; GLUT, glucose transporter; COX, cyclooxygenase; CA-IX, carbonic anhydrase 9; HIF, hypoxia-inducible factor; EPOR, erythropoietin receptor. ${ }^{\star} p<.05$.

Hypoxia is correlated with poor locoregional control and survival after radiotherapy for various types of cancer, including HNSCC, and is associated with decreased radiosensitivity. ${ }^{10,11}$ Recurrence in patients with HNSCC is associated with a poor prognosis and is the main cause of death. ${ }^{12}$ Therefore, extensive research efforts have focused on developing novel methods to improve tumor oxygenation, target hypoxic tumor cells, and otherwise modulate the effect of hypoxia on the response of tumors to radiation.

Several proteins are related to the transcriptional response to hypoxia and are expressed in tumor tissues. These include HIF-1 $\alpha$, CA-IX, and GLUT-1, which are currently being discussed as "endogenous hypoxia-related markers." 13

HIF- $1 \alpha$ is a transcription factor that responds to a decrease in oxygen levels within a cell and can be used as an indirect marker of tumor hypoxia. ${ }^{14}$ Furthermore, $\mathrm{HIF}-1 \alpha$ is a master gene that regulates the cellular response to hypoxia ${ }^{15}$ and promotes the transcription of CA-IX. CA-IX is 1 of 15 isoforms of carbonic anhydrase in humans and has recently emerged as one of the most promising endogenous hypoxia-related markers. ${ }^{16}$ GLUT1 is an integral membrane glycoprotein that plays a key role in facilitating glucose transport. Glucose uptake is increased in cancer cells, and increased expression of glucose transporters, especially GLUT-1, is frequently observed in many types of cancer. ${ }^{17}$ Studies show that these endogenous hypoxia-related markers are associated with a poor probability of locoregional control and with reduced overall and disease-free survival. ${ }^{18-20}$ However, other studies show no significant relationship between overexpression of endogenous hypoxia-related markers and clinical outcome..$^{21,22}$ In the present study, GLUT-1 was not correlated with poor clinical outcome. However, HIF- $1 \alpha$ and CA-IX levels were associated with poor locoregional control but not with disease-free survival. With regard to locoregional control, the incidence of residual tumor, but not tumor recurrence, was correlated with HIF-1 $\alpha$ and CA-IX expression; even the expression of 1 of the 2 markers was correlated with a higher prevalence of residual tumor. These results suggest that HIF$1 \alpha$ and CA-IX levels should be assessed in patients with early stage laryngeal carcinoma.

In addition to endogenous hypoxia-related markers, several immunohistochemical markers are associated with a poor clinical outcome in patients with cancer. The present study assessed the expression of $\mathrm{COX}-2, \mathrm{Ki}-67$, and EPOR. Two COX enzymes, COX-1 and COX-2, have been identified in human cells. COX-2 is an immediateearly response gene that is induced by a variety of stimuli and can rapidly elicit a response to tumor-promoting cytokines and growth factors through pathological pathways that affect mitosis, cell adhesion, and immune monitoring. Several recent studies confirmed that COX-2 plays a role in the development and prognosis of many cancers. ${ }^{23,24}$ However, other studies show that COX-2 expression does not have prognostic significance. ${ }^{25,26} \mathrm{Ki}-67$ is expressed exclusively in cells in the G1, S, G2, and mitotic phases. $^{27}$ Clinically, Ki-67 antigen detection is used to 

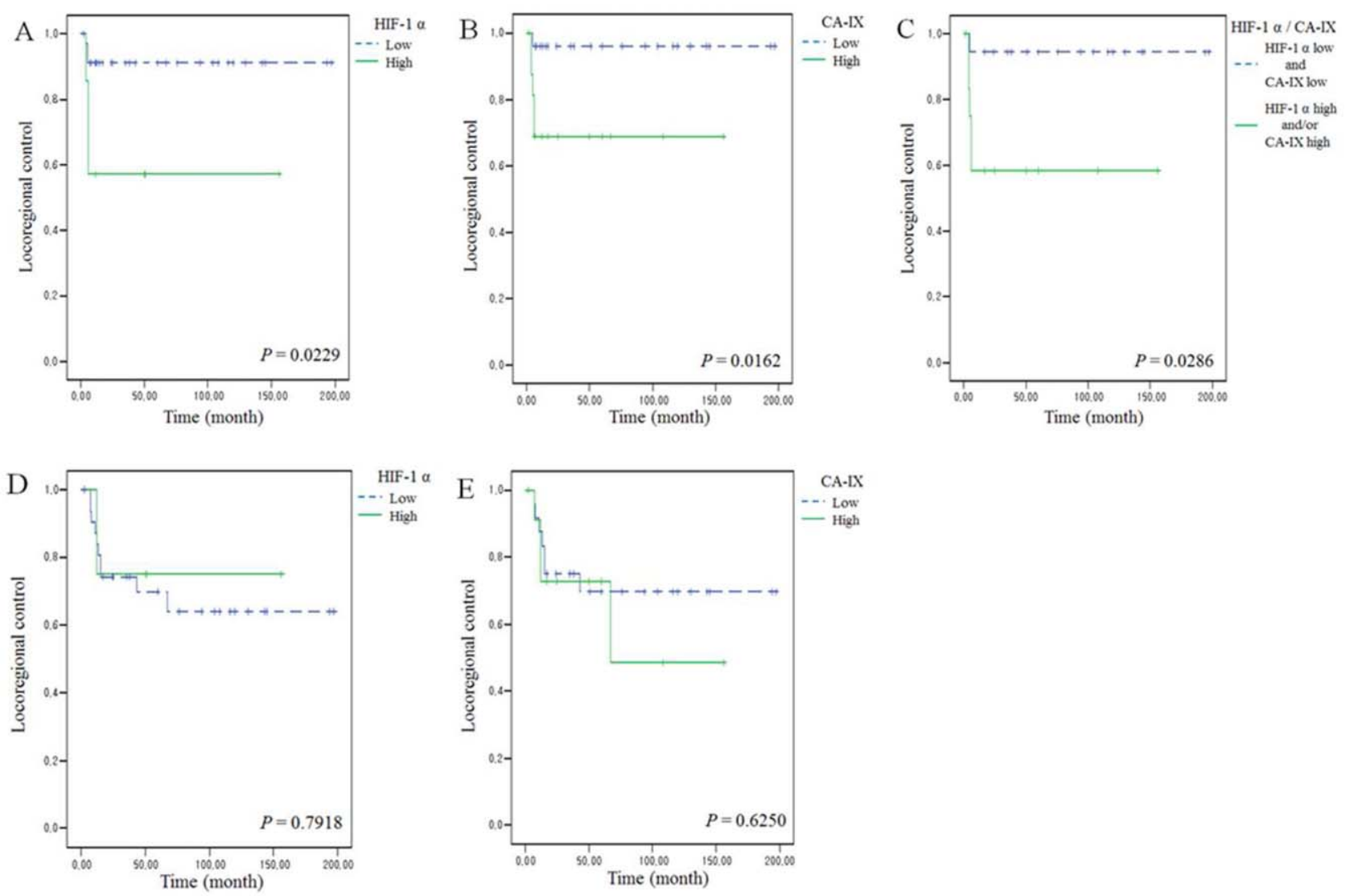

FIGURE 2. Kaplan-Meier survival curves were calculated for hypoxia-inducible factor (HIF) $-1 \alpha$ and carbonic anhydrase 9 (CA-IX). (A) HIF-1 $\alpha$ in residual tumor, (B) CA-IX in residual tumor, (C) HIF-1 $\alpha$ plus CA-IX in residual tumor, (D) HIF-1 $\alpha$ in recurrence, (E) CA-IX in recurrence. [Color figure can be viewed in the online issue, which is available at wileyonlinelibrary.com.]

estimate the growth rate of human malignant neoplasms, and, as a marker of active DNA synthesis, it is an indicator of the biological behavior of disease. ${ }^{28}$ However, the association between $\mathrm{Ki}-67$ expression and the prognosis of several cancers is controversial. Although the upregulation of Ki-67 expression is associated with neck metastasis, ${ }^{29,30}$ recurrence, and poor survival, ${ }^{31,32}$ some studies report a lack of association between $\mathrm{Ki}-67$ expression and survival. $^{33,34}$ The hypoxia-responsive hematopoietic factor, erythropoietin, is one of the molecules regulated by HIF. ${ }^{35}$ Erythropoietin and EPOR expression are associated with poor prognosis in patients with cancer. ${ }^{36}$ In the present study, these 3 markers were not correlated with poor locoregional control or survival.

Anemia is an important factor in the treatment outcome of patients with cancer, including patients with HNSCC. ${ }^{37}$ As the antitumor activity of radiotherapy is mediated by its interaction with oxygen to form labile free radicals, the intratumoral oxygen level affects the ability of radiotherapy to kill malignant cells. ${ }^{38}$ Anemia decreases the oxygen-carrying capacity of the blood, resulting in intratumor hypoxia and activation of the HIF pathway. In the present study, anemia was not correlated with the clinical outcome of patients with cancer, although few patients with anemia were included in the analysis.
The 6 immunohistochemical markers assessed in the present study may be potential prognostic factors for different cancers, including HNSCC. However, their usefulness as markers is controversial. Because of the importance of preserving laryngeal function, radiotherapy is the primary treatment for early-stage laryngeal carcinoma in most countries. However, approximately $15 \%$ to $20 \%$ of patients die from intercurrent disease within 5 years of radiotherapy. ${ }^{39}$ The identification of factors predictive of the success of locoregional control after radiotherapy may help determine the optimal treatment modality for patients with early-stage laryngeal carcinoma. The results of the present study indicate that HIF$1 \alpha$ and CA-IX may be useful markers of treatment outcome. In a previous study, high levels of HIF-1 $\alpha$ were associated with resistance to radiation in oral squamous

TABLE 3. Patient characteristics related to residual tumor after radiotherapy.

\begin{tabular}{lcc}
\hline Characteristic & Multivariate HR $(95 \% \mathrm{Cl})$ & $p$ value \\
\hline CA-IX & $72.290(3.239-1613.499)$ & $.007^{\star}$ \\
\hline
\end{tabular}

Abbreviations: HR, hazard ratio; $\mathrm{Cl}$, confidence interval; CA-IX, carbonic anhydrase 9. ${ }^{*} p<.05$. 
cell carcinoma cells, ${ }^{40}$ whereas a different study reported that HIF-1 $\alpha$ and CA-IX have no prognostic significance for predicting the failure of locoregional control in early glottic squamous cell carcinoma managed with radiotherapy. ${ }^{41}$ In the present study, increased expression of HIF$1 \alpha$ and CA-IX was a statistically significant predictor of residual tumor, but was not associated with locoregional recurrence or disease-specific survival, suggesting that HIF- $1 \alpha$ and CA-IX are associated with radioresistance.

\section{CONCLUSION}

HIF- $1 \alpha$ and CA-IX are predictive of residual tumor, but not recurrence, in patients with early-stage laryngeal carcinoma treated with radiotherapy alone. Therefore, HIF- $1 \alpha$ and CA-IX may be useful for identifying patients who would benefit from alternative treatment modalities other than primary radiotherapy.

\section{REFERENCES}

1. Parkin DM, Bray F, Ferlay J, Pisani P. Estimating the world cancer burden: Globocan 2000. Int J Cancer 2001;94:153-156.

2. Boring CC, Squires TS, Tong T, Montgomery S. Cancer statistics, 1994. CA Cancer J Clin 1994;44:7-26.

3. Vaupel P, Mayer A, Höckel M. Tumor hypoxia and malignant progression. Methods Enzymol 2004;381:335-354.

4. Bussink J, Kaanders JH, van der Kogel AJ. Tumor hypoxia at the microregional level: clinical relevance and predictive value of exogenous and endogenous hypoxic cell markers. Radiother Oncol 2003;67:3-15.

5. Rockwell S, Dobrucki IT, Kim EY, Marrison ST, Vu VT. Hypoxia and radiation therapy: past history, ongoing research, and future promise. Curr Mol Med 2009;9:442-458.

6. Schrijvers ML, van der Laan BF, de Bock GH, et al. Overexpression of intrinsic hypoxia markers HIF1alpha and CA-IX predict for local recurrence in stage T1-T2 glottic laryngeal carcinoma treated with radiotherapy. Int J Radiat Oncol Biol Phys 2008;72:161-169.

7. Koukourakis MI, Giatromanolaki A, Sivridis E, et al. Hypoxia-activated tumor pathways of angiogenesis and $\mathrm{pH}$ regulation independent of anemia in head-and-neck cancer. Int J Radiat Oncol Biol Phys 2004;59:67-71.

8. Hirasawa N, Itoh Y, Naganawa S, et al. Multi-institutional analysis of early glottic cancer from 2000 to 2005. Radiat Oncol 2012;7:122.

9. Moeller BJ, Richardson RA, Dewhirst MW. Hypoxia and radiotherapy: opportunities for improved outcomes in cancer treatment. Cancer Metastasis Rev 2007;26:241-248.

10. Vaupel P, Mayer A. Hypoxia in cancer: significance and impact on clinical outcome. Cancer Metastasis Rev 2007;26:225-239.

11. Vordermark D, Brown JM. Endogenous markers of tumor hypoxia predictors of clinical radiation resistance? Strahlenther Onkol 2003;179:801-811.

12. Alvarez Marcos CA, Llorente Pendás JL, Franco Gutiérrez V, et al. Tumour recurrence in squamous head and neck cancer [in Spanish]. Acta Otorrinolaringol Esp 2007;58:156-163.

13. Jonathan RA, Wijffels KI, Peeters W, et al. The prognostic value of endogenous hypoxia-related markers for head and neck squamous cell carcinomas treated with ARCON. Radiother Oncol 2006;79:288-297.

14. Aebersold DM, Burri P, Beer KT, et al. Expression of hypoxia-inducible factor-1alpha: a novel predictive and prognostic parameter in the radiotherapy of oropharyngeal cancer. Cancer Res 2001;61:2911-2916.

15. Zagórska A, Dulak J. HIF-1: the knowns and unknowns of hypoxia sensing. Acta Biochim Pol 2004;51:563-585.

16. Kaluz S, Kaluzová M, Liao SY, Lerman M, Stanbridge EJ. Transcriptional control of the tumor- and hypoxia-marker carbonic anhydrase 9: a one transcription factor (HIF-1) show? Biochim Biophys Acta 2009;1795:162-172.

17. Macheda ML, Rogers S, Best JD. Molecular and cellular regulation of glucose transporter (GLUT) proteins in cancer. J Cell Physiol 2005;202:654-662.

18. Li DW, Zhou L, Jin B, Xie J, Dong P. Expression and significance of hypoxia-inducible factor- $1 \alpha$ and survivin in laryngeal carcinoma tissue and cells. Otolaryngol Head Neck Surg 2013;148:75-81.

19. Rademakers SE, Hoogsteen IJ, Rijken PF, et al. Pattern of CAIX expression is prognostic for outcome and predicts response to ARCON in patients with laryngeal cancer treated in a phase III randomized trial. Radiother Oncol 2013;108:517-522.

20. Ohba S, Fujii H, Ito S, et al. Overexpression of GLUT-1 in the invasion front is associated with depth of oral squamous cell carcinoma and prognosis. J Oral Pathol Med 2010;39:74-78.

21. Hui EP, Chan AT, Pezzella F, et al. Coexpression of hypoxia-inducible factors 1alpha and 2alpha, carbonic anhydrase IX, and vascular endothelial growth factor in nasopharyngeal carcinoma and relationship to survival. Clin Cancer Res 2002;8:2595-2604.

22. Eriksen JG, Overgaard J; Danish Head and Neck Cancer Study Group (DAHANCA). Lack of prognostic and predictive value of CA IX in radiotherapy of squamous cell carcinoma of the head and neck with known modifiable hypoxia: an evaluation of the DAHANCA 5 study. Radiother Oncol 2007;83:383-388.

23. Lin PC, Lin YJ, Lee CT, Liu HS, Lee JC. Cyclooxygenase-2 expression in the tumor environment is associated with poor prognosis in colorectal cancer patients. Oncol Lett 2013;6:733-739.

24. Morita Y, Hata K, Nakanishi M, Nishisho T, Yura Y, Yoneda T. Cyclooxygenase-2 promotes tumor lymphangiogenesis and lymph node metastasis in oral squamous cell carcinoma. Int J Oncol 2012;41:885-892.

25. Park BW, Park S, Park HS, et al. Cyclooxygenase-2 expression in proliferative Ki-67-positive breast cancers is associated with poor outcomes. Breast Cancer Res Treat 2012;133:741-751.

26. Atula T, Hedström J, Ristimäki A, et al. Cyclooxygenase-2 expression in squamous cell carcinoma of the oral cavity and pharynx: association to p53 and clinical outcome. Oncol Rep 2006;16:485-490.

27. Gerdes J, Lemke H, Baisch H, Wacker HH, Schwab U, Stein H. Cell cycle analysis of a cell proliferation-associated human nuclear antigen defined by the monoclonal antibody Ki-67. J Immunol 1984;133:1710-1715.

28. Gerdes J, Li L, Schlueter C, et al. Immunobiochemical and molecular biologic characterization of the cell proliferation-associated nuclear antigen that is defined by monoclonal antibody Ki-67. Am J Pathol 1991;138:867873 .

29. Matsumoto M, Komiyama K, Okaue M, et al. Predicting tumor metastasis in patients with oral cancer by means of the proliferation marker Ki67. $J$ Oral Sci 1999:41:53-56.

30. Liu M, Lawson G, Delos M, et al. Predictive value of the fraction of cancer cells immunolabeled for proliferating cell nuclear antigen or Ki67 in biopsies of head and neck carcinomas to identify lymph node metastasis: comparison with clinical and radiologic examinations. Head Neck 2003;25: 280-288.

31. Koo TR, Eom KY, Kang EY, et al. Prognostic value of the nodal ratio and ki-67 expression in breast cancer patients treated with postmastectomy radiotherapy. J Breast Cancer 2013;16:274-284.

32. Montebugnoli L, Badiali G, Marchetti C, Cervellati F, Farnedi A, Foschini MP. Prognostic value of Ki67 from clinically and histologically 'normal' distant mucosa in patients surgically treated for oral squamous cell carcinoma: a prospective study. Int J Oral Maxillofac Surg 2009;38:1165-1172.

33. Gonzalez-Moles MA, Ruiz-Avila I, Gil-Montoya JA, Esteban F, Bravo M. Analysis of Ki-67 expression in oral squamous cell carcinoma: why Ki67 is not a prognostic indicator. Oral Oncol 2010;46:525-530.

34. Perisanidis C, Perisanidis B, Wrba F, et al. Evaluation of immunohistochemical expression of p53, p21, p27, cyclin D1, and Ki67 in oral and oropharyngeal squamous cell carcinoma. J Oral Pathol Med 2012;41:40-46.

35. Morais C, Johnson DW, Vesey DA, Gobe GC. Functional significance of erythropoietin in renal cell carcinoma. BMC Cancer 2013;13:14.

36. Henke M, Mattern D, Pepe M, et al. Do erythropoietin receptors on cancer cells explain unexpected clinical findings? J Clin Oncol 2006;24:47084713.

37. Harrison LB, Chadha M, Hill RJ, Hu K, Shasha D. Impact of tumor hypoxia and anemia on radiation therapy outcomes. Oncologist 2002; 492-508.

38. Harrison LB, Shasha D, Homel P. Prevalence of anemia in cancer patients undergoing radiotherapy: prognostic significance and treatment. Oncology 2002;63 Suppl 2:11-18.

39. Mendenhall WM, Werning JW, Hinerman RW, Amdur RJ, Villaret DB. Management of T1-T2 glottic carcinomas. Cancer 2004;100:17861792.

40. Hosokawa Y, Okumura K, Terashima S, Sakakura Y. Radiation protective effect of hypoxia-inducible factor- $1 \alpha$ (HIF-1 $\alpha)$ on human oral squamous cell carcinoma cell lines. Radiat Prot Dosimetry 2012;152: 159-163.

41. Douglas CM, Bernstein JM, Ormston VE, et al. Lack of prognostic effect of carbonic anhydrase-9, hypoxia inducible factor- $1 \alpha$ and bcl-2 in 286 patients with early squamous cell carcinoma of the glottic larynx treated with radiotherapy. Clin Oncol (R Coll Radiol) 2013;25:59-65. 